\title{
Extramedullary plasmacytoma of the dura mimicking meningioma
}

\author{
Masahiro Manabe $\cdot$ Hiroshi Kanashima $\cdot$ Yumi Yoshii $\cdot$ Satoru Mukai $\cdot$ \\ Erina Sakamoto · Yoshiyasu Iwai · Yuki Kubo · Hiroko Fukushima • \\ Takeshi Inoue $\cdot$ Hirofumi Teshima
}

Received: 22 January 2010/Revised: 4 April 2010/Accepted: 22 April 2010/Published online: 15 May 2010

(C) The Japanese Society of Hematology 2010

In December 2005, a 59-year-old man presented at our Neurosurgery Department with a 2-month history of amnesia and gait disturbance. A solid mass lesion was detected in the right temporal region on magnetic resonance imaging (MRI), presumed to be a meningioma (Fig. 1). He underwent surgery via a right temporal frontal craniotomy and partial resection of the mass. Biopsy of the mass demonstrated a densely cellular tumor composed of plasma cells, positive for IgG and kappa light chain (Fig. 2), and negative for lambda chain, CD56 and cyclin D1. These findings were consistent with intracranial plasmacytoma.

No additional sites of plasmacytoma were identified on either computed tomography or bone scintigraphy, and bone marrow plasmacytosis was absent $(1.8 \%$ plasma cells, morphologically normal), and bone marrow cells showed a normal karyotype. Serum immunoglobulin levels were almost normal (IgG 1,374 mg/dL, IgA $443 \mathrm{mg} / \mathrm{dL}, \operatorname{IgM}$ $54 \mathrm{mg} / \mathrm{dL}, \operatorname{IgE} 81 \mathrm{IU} / \mathrm{mL}, \operatorname{IgD} 7.6 \mathrm{mg} / \mathrm{dL}$ ), and postoperative serum protein immunoelectrophoresis showed a small

M. Manabe $(\bowtie) \cdot$ H. Kanashima · Y. Yoshii · S. Mukai .

E. Sakamoto $\cdot$ H. Teshima

Department of Hematology, Osaka City General Hospital,

2-13-22 Miyakojimahondori, Miyakojima-Ku,

Osaka 534-0021, Japan

e-mail: m1153564@med.osaka-cu.ac.jp

Y. Iwai

Department of Neurosurgery, Osaka City General Hospital,

Osaka, Japan

Y. Kubo $\cdot$ H. Fukushima $\cdot$ T. Inoue

Department of Pathology, Osaka City General Hospital,

Osaka, Japan
M-component only (IgG- $\kappa$ ). Urine Bence-Jones protein was not detected. Other organopathies, such as nephropathy, hypercalcemia and bone region, were absent. Thus, a diagnosis of extramedullary plasmacytoma was made according to the classification of the International Myeloma Working Group (IMWG) [1]. He underwent external beam radiotherapy to the brain at a dosage of $50 \mathrm{~Gy}$, which resulted in the disappearance of the remaining tumor region.

In January 2007, he developed hoarseness and thoracic pain. Since CT scans demonstrated new masses at other sites (rib and vertebral bones), he was diagnosed with disease progression. Laboratory findings showed an increased total serum protein of $8.6 \mathrm{~g} / \mathrm{dL}, \mathrm{IgG} 3,629 \mathrm{mg} / \mathrm{dL}$, and serum protein immunoelectrophoresis revealed an evident $\mathrm{M}$-component of IgG- $\kappa$. Bone marrow examination showed no evidence of plasmacytosis (2.4\% plasma cells, without atypia) and chromosomal analysis revealed a normal karyotype. Thereafter, he received several courses of chemotherapy with vincristine, doxorubicin and dexamethasone. Despite treatment, regrowth of the mass was observed. He refused further therapy and was discharged from our hospital.

Patients with a solitary dural plasmacytoma have been reported with a female predominance of $84 \%$ and a mean age of 50.2 years. Clinically, combination therapy including surgical resection followed by at least 50 Gy radiotherapy is recommended, and long-term survival has been observed. On the other hand, patients with myelomatous meningeal involvement have shown an extremely poor prognosis despite intensified treatment, including intrathecal and/or systemic chemotherapy and cranial radiotherapy [2]. Our patient showed a recurrence almost 1 year after the initial diagnosis. We consider that postoperative radiotherapy was delayed by about 2 months because of intensive care, which might have caused the early recurrence. 


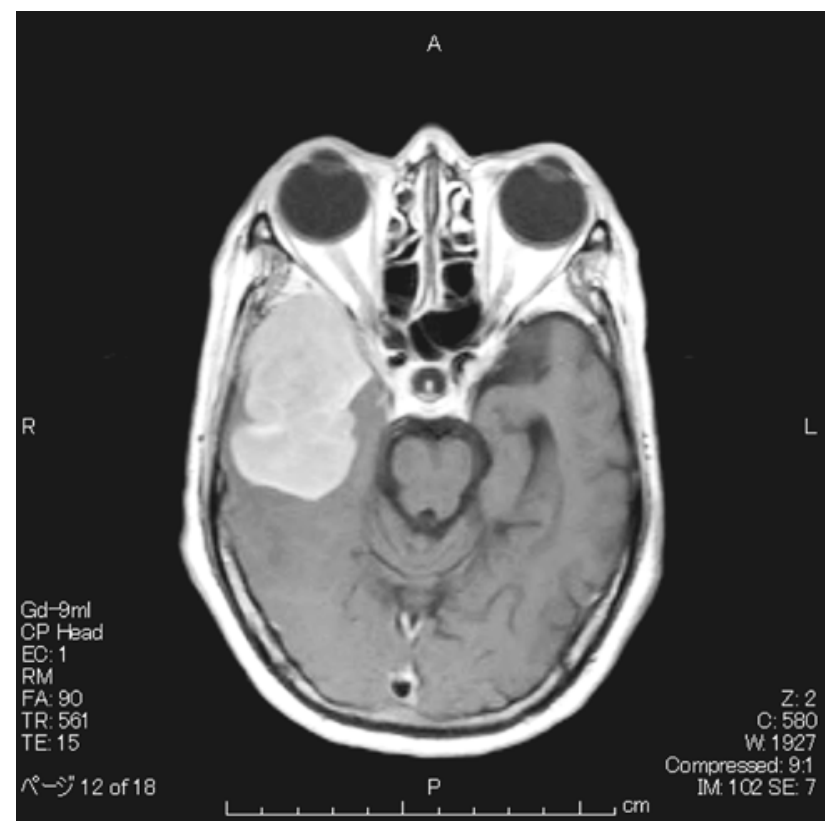

Fig. 1 Gadolinium-enhanced T1-weighted MR image showing the mass

Finally, many tumors, such as metastases of carcinomas from the breast, colon, lung and renal cells, or nonneoplastic lesions, such as subdural hematomas arising from the dura mimicking meningiomas, have been reported, but intracranial plasmacytoma is relatively rare. We consider that plasmacytoma should be included in the differential diagnosis of meningioma.

\section{References}

1. International Myeloma Working Group. Criteria for the classification of monoclonal gammopathies, multiple myeloma and related disorders: a report of the International Myeloma Working Group. Br J Haematol. 2003;121:749-57.
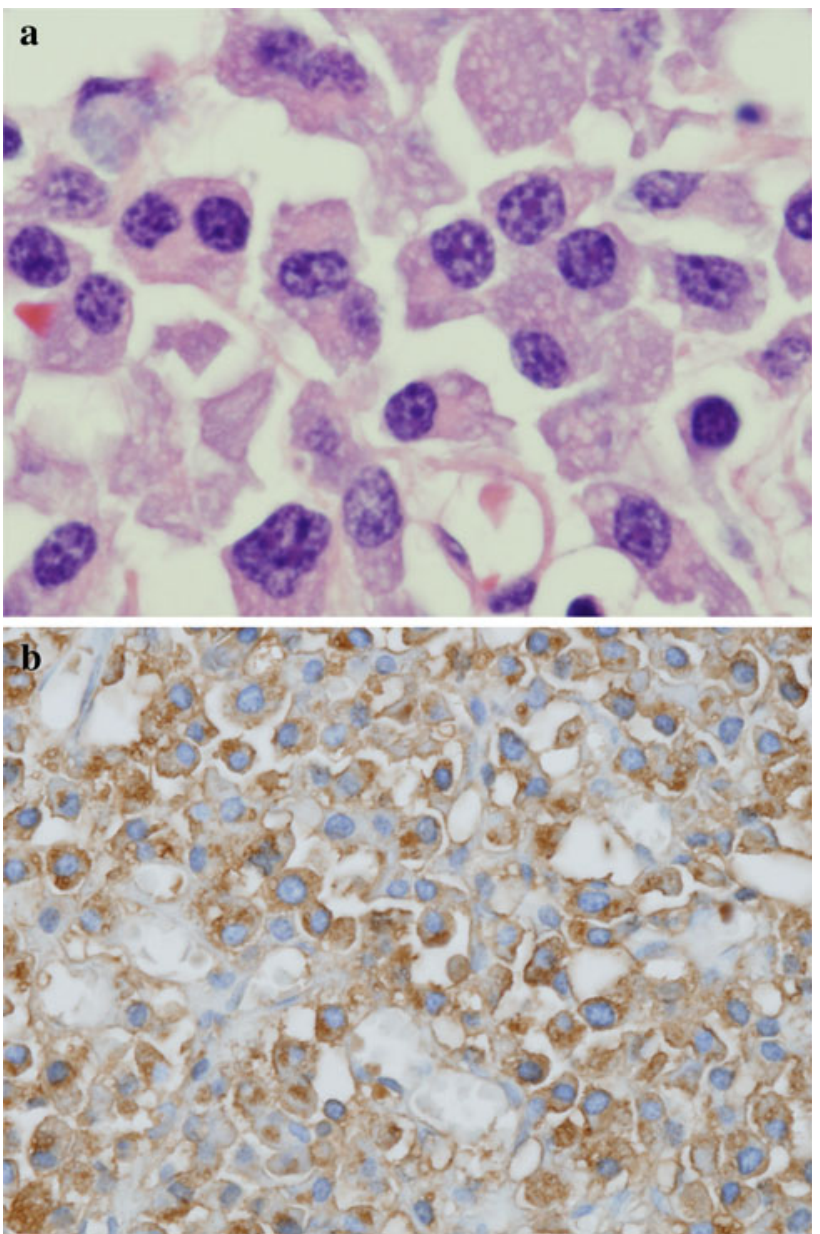

Fig. 2 Pathological examination of the surgical specimen showing infiltration by plasma cells. $\mathrm{H} \& \mathrm{E}$ stain (a) and immunohistochemical stain with $\operatorname{IgG}(\mathbf{b})$

2. Haegelen C, Riffaud L, Bernard M, Carsin-Nicol B, Morandi X. Dural plasmacytoma revealing multiple myeloma. J Neurosurg. 2006;104:608-10. 